\title{
LANDFORM MONITORING IN ACTIVE VOLCANO BY UAV AND SFM-MVS TECHNIQUE
}

\author{
T. Nakano ${ }^{\text {a, } * \text {, I. Kamiya }}{ }^{\text {a }}$, M. Tobita ${ }^{\text {a }}$, J. Iwahashi ${ }^{\text {a }}$, H. Nakajima ${ }^{\text {a }}$ \\ ${ }^{\text {a }}$ Geospatial Information Authority of Japan, 1 Kitasato, Tsukuba, Ibaraki, Japan \\ - (t-nakano, kamiya, tobita, iwahashi, nakajima)@ gsi.go.jp
}

Commission VIII, WG VIII/1

KEY WORDS: Unmanned Aerial Vehicle (UAV), Aerial Photogrammetry, Structure from Motion (SfM), Multi-view Stereo (MVS), Nishinoshima volcano, Digital Elevation Model (DEM), Ortho-Mosaic Photo

\begin{abstract}
:
Nishinoshima volcano in Ogasawara Islands has erupted since November, 2013. This volcanic eruption formed and enlarged a new island, and fused the new island with the old Nishinoshima Island. We performed automated aerial photographing using an Unmanned Aerial Vehicle (UAV) over the joined Nishinoshima Island on March 22 and July 4, 2014. We produced ortho-mosaic photos and digital elevation model (DEM) data by new photogrammetry software with computer vision technique, i.e. Structure from Motion (SfM) for estimating the photographic position of the camera and Multi-view Stereo (MVS) for generating the 3-D model. We also estimated the area and volume of the new island via analysis of ortho-mosaic photo and DEM data. Transition of volume estimated from the UAV photographing and other photographing shows the volcanic activity still keeps from initial level. The ortho-mosaic photos and DEM data were utilized to create an aerial photo interpretation map and a 3-D map. These operations revealed new knowledge and problems to be solved on the photographing and analysis using UAV and new techniques as this was first case in some respects.
\end{abstract}

\section{INTRODUCTION}

Unmanned Aerial Vehicle (UAV) system is recently applied in many fields, e.g. disaster, environment, agriculture and archaeological investigation, observation of man-made objects such as bridge and dam site, acquisition of spatial information in local area and zone where a man is hard to enter (e.g. Yan et al., 2003; Bendea et al., 2008; Watabe and Sassa, 2009; Maza et al., 2011; Rinaudo et al., 2012; Inoue et al., 2014). Also, a public survey using UAV has started in Japan.

In parallel with this, a new-common procedure of a computer vision technology, called Structure from Motion (SfM) for estimating the photographic position of the camera and Multiview Stereo (MVS) to generate the 3-D model has become common in recent years. The SfM-MVS technique easily produces high dense point clouds. Scale invariant features provide reliable matching between different views of images (Lowe, 2004). The bundle adjustment algorithm automatically detect interior and exterior orientations for large unstructured collections of photographs and 3-D point clouds are reconstructed simultaneously (Snavely et al., 2006; Agarwal et al., 2009). Combination of this technique and UAV system is able to produce an ortho-mosaic photo and digital surface model (DSM) data conveniently from aerial photos (e.g. Gerke and Kerle, 2011; Uchiyama et al., 2014).

On the other hand, volcanic eruption started off the coast of Nishinoshima volcano in Ogasawara Islands (Figure 1) and formation of new island was observed on November 20, 2013. Because the eruption with lava outflow continue, it is impossible to make a landing and ground observation at the present time (on
September, 2014). So, we only rely on the observation from the sky.

Outflow volume of lava per day estimated from volume transition of new island is important index for evaluation and prediction of volcanic activity. Photogrammetric method is able to produce accurate digital elevation model (DEM) data and to calculate volume above sea level.

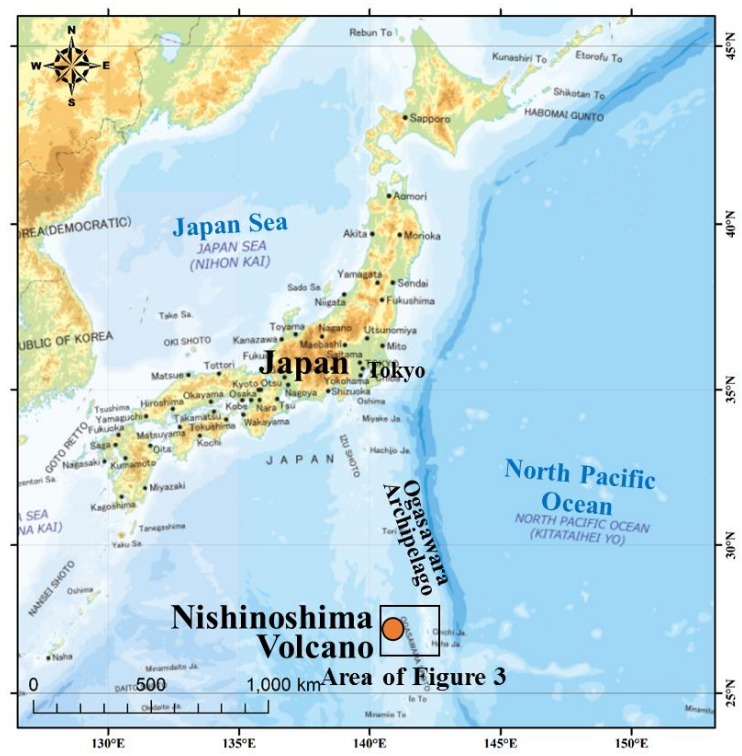

Figure 1. Position of Nishinoshima Volcano (on romanized GSI map)

\footnotetext{
* Corresponding author.
} 
So, we performed automated aerial photographing using a UAV on March 22 and July 4, 2014, and produced ortho-mosaic photos and DEM data using new photogrammetry software with SfM-MVS technique. Also, we estimated the area and volume of new island via analysis of ortho-mosaic photos and DEM data.

\section{AERIAL PHOTOGRAPHING IN NISHINOSHIMA VOLCANO}

\subsection{Photographing implements}

The UAV used on the aerial photographing is fixed-wing aircraft with 86 cc two-stroke gasoline engine; a total length of 2,200 $\mathrm{mm}$, total width of $2,800 \mathrm{~mm}$, weight of $15 \mathrm{~kg}$, maximum takeoff weight of $35 \mathrm{~kg}$, , cruising speed of $120 \mathrm{~km} / \mathrm{h}$, flight time of 4.5 hours, flight distance of about $500 \mathrm{~km}$ (Figure 2). The UAV has autonomic aviation control capability and flight capability through use of an autopilot based on an inertial navigation device. This UAV belongs to Air Photo Service Inc., Japan and the flight operations were performed by the company.

The camera used in the aerial photographing was Canon EOS 5D Mark II (35 mm full size single-lens reflex camera). The used lens was Canon EF28mm F1.8 USM ( $28 \mathrm{~mm}$ single focus). The focus was fixed on infinity. On March 22, shutter speed was fixed at 1/800 second and diaphragm was set to auto. On July 4, diaphragm was fixed at " $\mathrm{f} / 8$ " and shutter speed was set to auto based on the previous experience. The shutter was released every second synchronizing with observation of GPS mounted on the UAV body. This camera was calibrated after the operation.

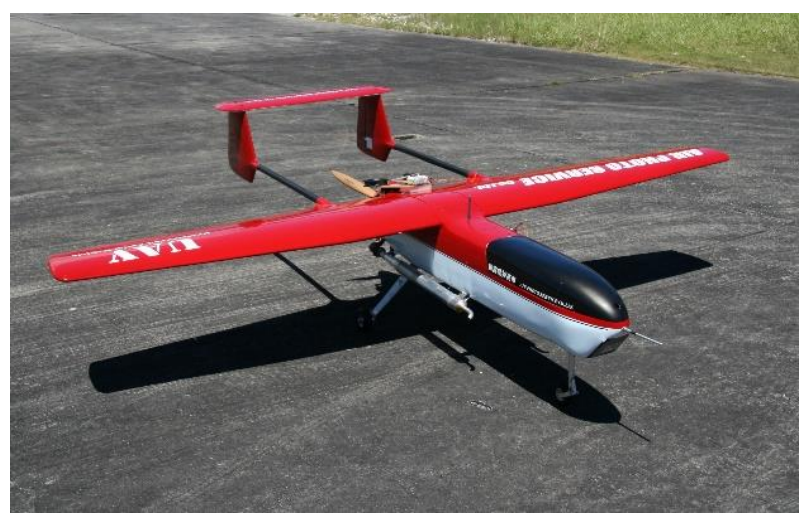

Figure 2. UAV used on the aerial photographing

\subsection{Flight path and condition}

As the inhabited island nearest Nishinoshima Volcano is Chichijima Island (Figure 3), the UAV flied from Chichijima Island to Nishinoshima Volcano and back. The flight path is also shown in Figure 3. On March 22, the UAV took off at 11:05, started aerial photographing at 12:35 above Nishinoshima Volcano, finished aerial photographing at 12:47, and landed at 13:56 on Chichijima Island. On July 4, the UAV took off at 10:04, started aerial photographing at 11:35 above Nishinoshima Volcano, finished aerial photographing at 11:51, and landed at 13:02. Total flight times are 2 hours 51 minutes and 2 hours 58 minutes, respectively.

The UAV flied 3 north-south courses (altitude of $800 \mathrm{~m}$ ) and 1 east-west course $(1,400 \mathrm{~m})$ on March 22 , and 6 north-south courses and 5 east-west courses (both $700 \mathrm{~m}$ ) on July 4 above Nishinoshima Volcano.

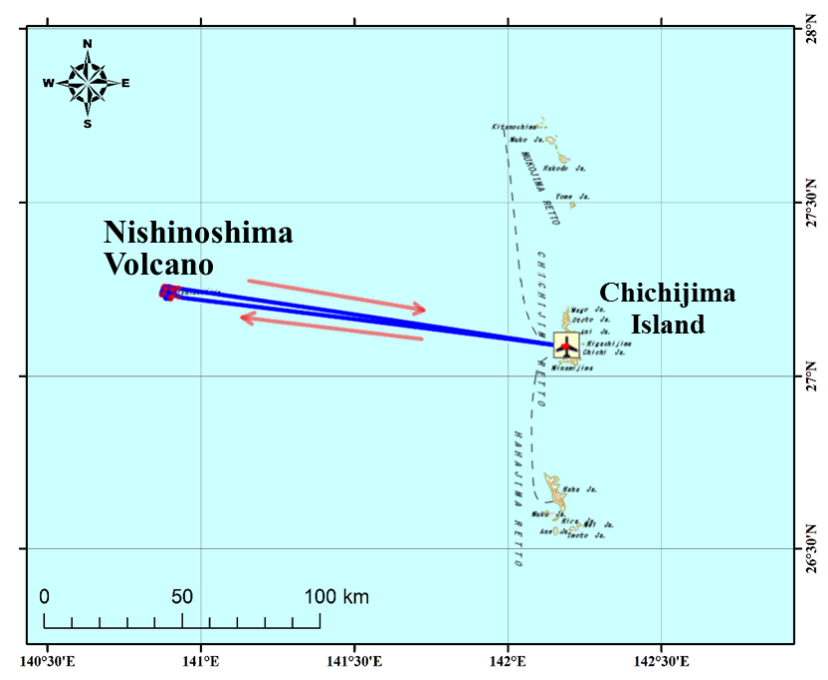

Figure 3. Flight path from Chichijima Island to Nishinoshima Volcano (on romanized GSI map)

\section{ANALYSIS RESULT OF UAV AERIAL PHOTOS}

The UAV took 463 images of Nishinoshima Island and surrounding ocean on March 22 and 1,107 images on July 4. We produced DEM data and ortho-mosaic photos using these photos and the analysis software "Pix4Dmapper" (Vallet et al., 2011). The process consists of three steps as follows: 1) an aerial triangulation process, 2) a generation of point cloud, 3) a generation of DEM data and ortho-mosaic photo.

On the aerial triangulation process by "Pix4Dmapper", a lot of path points were generated automatically by the "Multi ray matching" command (Figure 4). The ground control points (GCPs) were acquired at previous Nishinoshima Island using DEM data and ortho-mosaic photos, which were produced by traditional photogrammetry using a manned aerial vehicle and a photogrammetric camera on December 17, 2013. Because the distribution of these control points was biased, height control points were observed at calm coasts refereeing tidal observation at Chichijima Island.

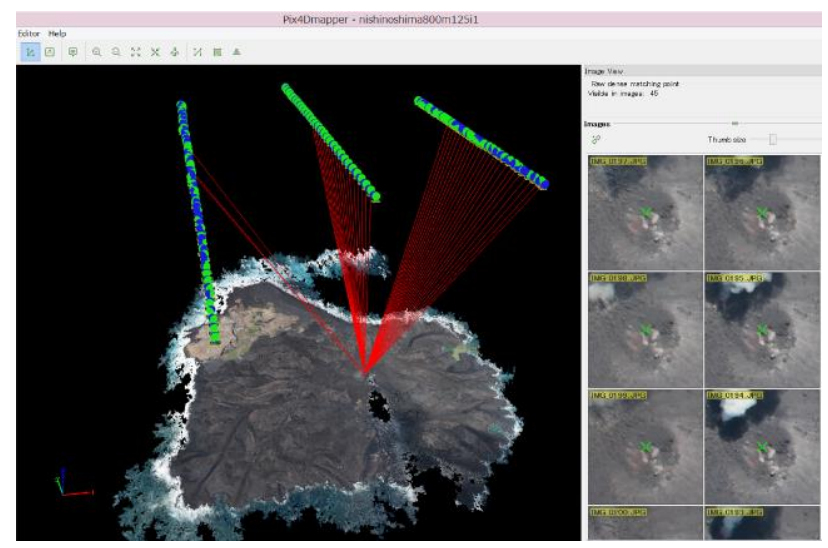

Figure 4 Multi ray matching image by "Pix4Dmapper" 
If all photos were used on the analysis, many path points were generated on the sea surface. Therefore, we typically used every fourth photos.

\subsection{Ortho-mosaic photo}

Figure 5 is the ortho-mosaic photo of Nishinoshima Volcano on March 22 and July 4 by analysis described above.
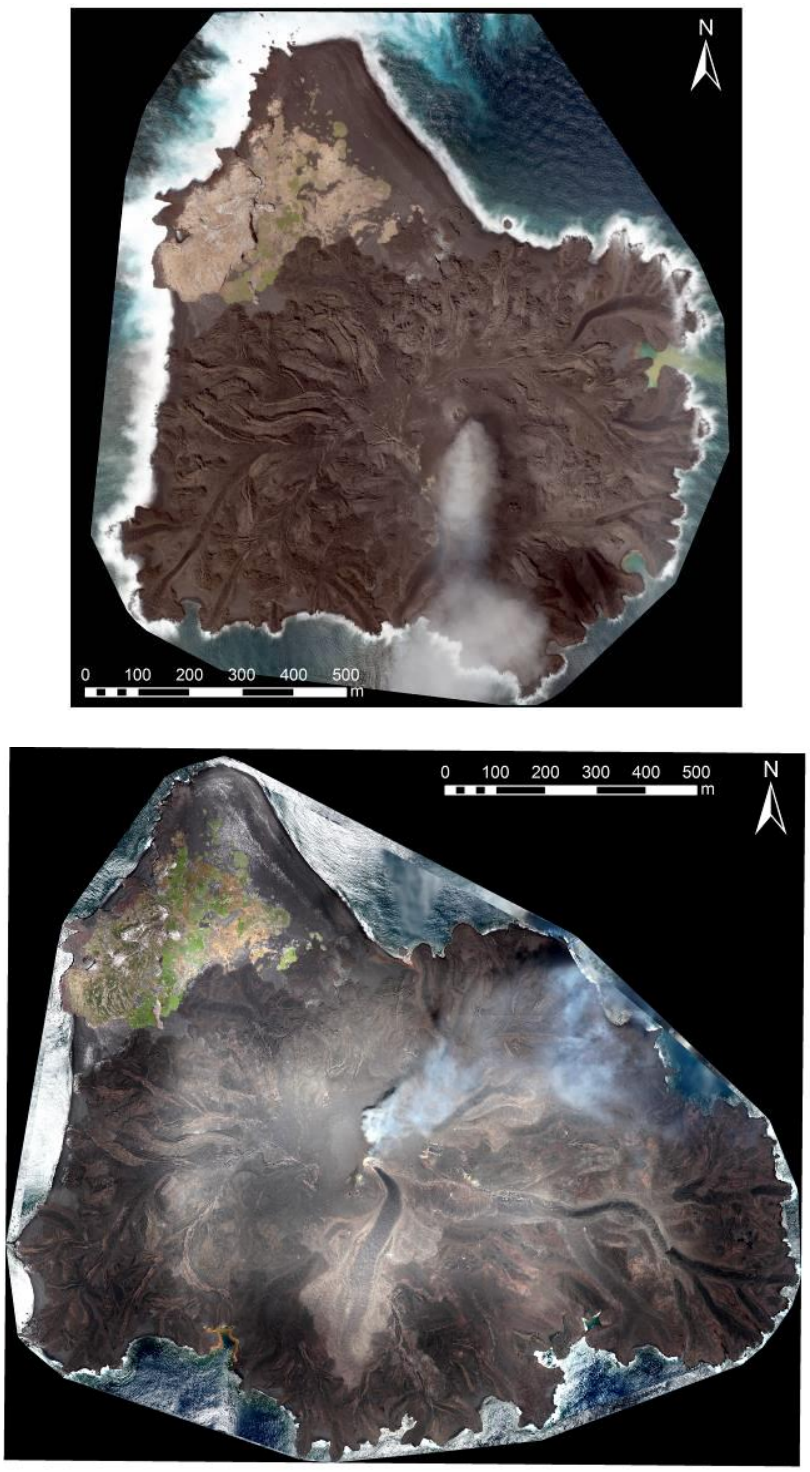

Figure 5 Ortho-mosaic photo of Nishinoshima Volcano on March 22 (upper figure) and July 7 (lower figure), 2014.

\subsection{DEM data}

We generated $2.5 \mathrm{~m}$ grid DEM data. Shading map using the DEM data on March 22 and July 4 are shown in Figure 6. Grid size of the original DEM data was $0.2 \mathrm{~m}$. The highest elevation was estimated approximately $71 \mathrm{~m}$ on March 22 and $74 \mathrm{~m}$ on July 4 . In addition, both highest peaks were approximately 100 m away.

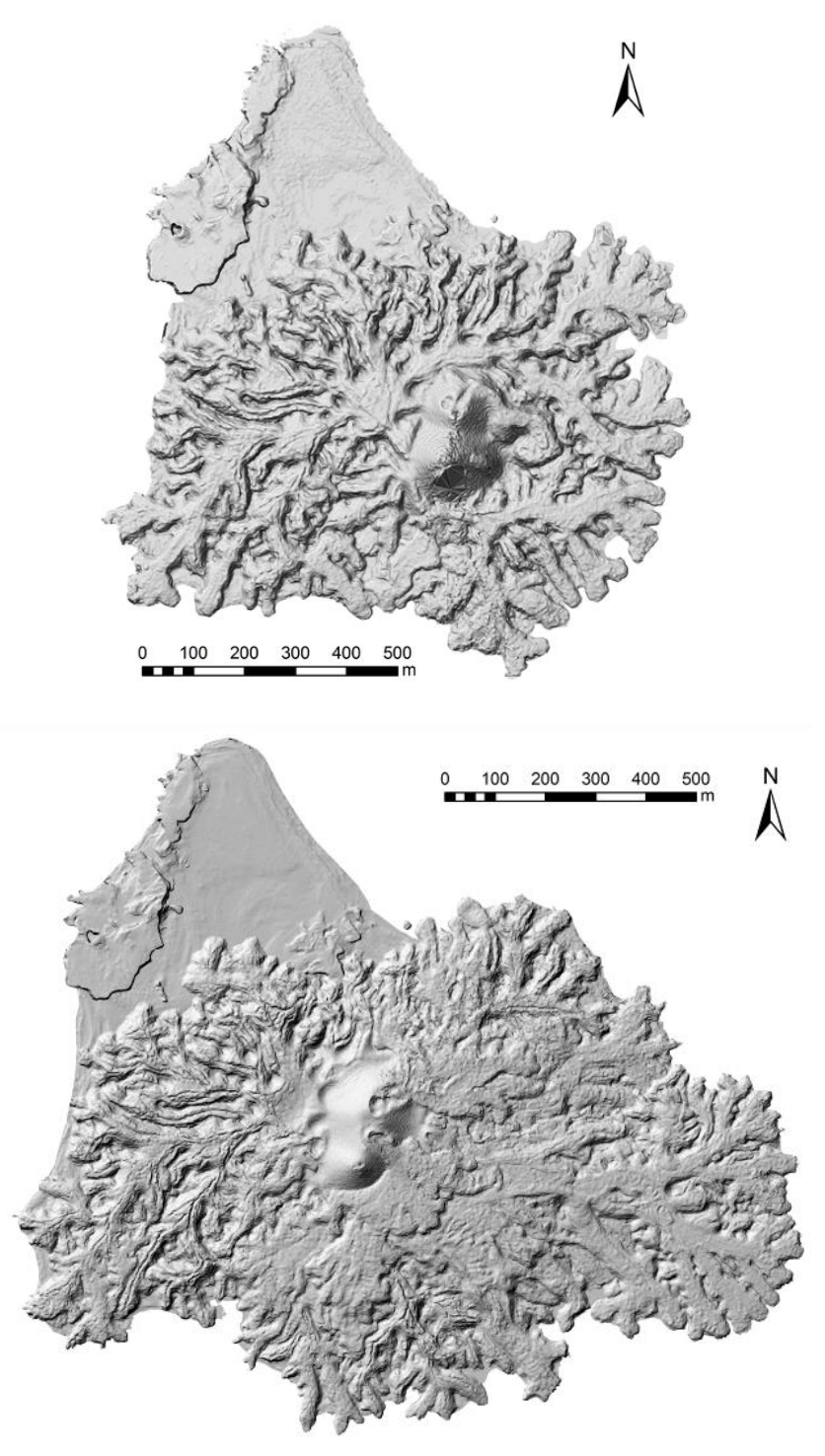

Figure 6 Shading map of Nishinoshima Volcano on March 22 (upper figure) and July 4 (lower figure), 2014.

\subsection{Area, volume and these transition}

Aerial photos of Nishinoshima Volcano were also taken on December 4, 2013, December 17, 2013 and February 16, 2014 by Geospatial Information Authority of Japan. These aerial photos were taken via formal surveying device (airplane, camera and GNSS receiver), and DEM data and ortho-mosaic photos were generated in every period. Table 1 shows the area, the highest elevation, the volume above sea level and transition ratio of volume above sea level of new island based on the four times photographing, except for December 4, 2013.

The area and volume of new island by this analysis were 0.67 $\mathrm{km}^{2}$ and 11.3 million $\mathrm{m}^{3}$ on March 22, and $1.08 \mathrm{~km}^{2}$ and 22.2 million $\mathrm{m}^{3}$ on July 4 , respectively. The transition ratio of volume above sea level calculated from both volume was approximately 0.1 million $\mathrm{m}^{3} /$ day. There were no large changes in the transition ratio trend compared with other period. This indicates that flow out of lava has not still slowed down. 
In addition, we verified the error from the difference of analysis software. We generated DEM data and ortho-mosaic photo from aerial photos on February 16, 2014 by "Pix4Dmapper" and compared with the result of traditional photogrammetry. As a result, the difference of highest elevation, area and volume were $0 \mathrm{~m}, 0.01 \mathrm{~km}^{2}$, and 0.1 million $\mathrm{m}^{3}$ respectively. So, we judged that the error from the difference of analysis software was sufficiently small.

Table 1 Area, the highest elevation, volume above sea level and transition ratio of volume of new island based on the four times photographing

\begin{tabular}{|c|c|c|c|c|}
\hline Date & $\begin{array}{l}\text { Area of } \\
\text { new } \\
\text { island }\end{array}$ & $\begin{array}{c}\text { The } \\
\text { highest } \\
\text { elevation }\end{array}$ & $\begin{array}{c}\text { Volume } \\
\text { above sea } \\
\text { level of } \\
\text { new island }\end{array}$ & $\begin{array}{l}\text { Transition } \\
\text { ratio of } \\
\text { lava above } \\
\text { sea level }\end{array}$ \\
\hline \multirow{2}{*}{$\begin{array}{c}\text { Dec. 17, } 2013 \\
\text { (by formal } \\
\text { device) }\end{array}$} & \multirow{2}{*}{$\begin{array}{l}0.097 \\
\mathrm{~km}^{2}\end{array}$} & \multirow[t]{2}{*}{$39 \mathrm{~m}$} & \multirow{2}{*}{$\begin{array}{c}0.8 \text { million } \\
\mathrm{m}^{3}\end{array}$} & \\
\hline & & & & \multirow{2}{*}{$\begin{array}{c}0.12 \\
\text { million } \\
\mathrm{m}^{3} / \text { day }\end{array}$} \\
\hline \multirow{2}{*}{$\begin{array}{c}\text { Feb. 16, } 2014 \\
\text { (by formal } \\
\text { device) }\end{array}$} & \multirow[t]{2}{*}{$0.51 \mathrm{~km}^{2}$} & \multirow{2}{*}{$66 \mathrm{~m}$} & \multirow{2}{*}{$\begin{array}{c}7.9 \text { million } \\
\mathrm{m}^{3}\end{array}$} & \\
\hline & & & & 0.10 \\
\hline \multirow{2}{*}{$\begin{array}{c}\text { Mar. 22, } 2014 \\
\text { (by UAV) }\end{array}$} & \multirow{2}{*}{$0.67 \mathrm{~km}^{2}$} & \multirow{2}{*}{$71 \mathrm{~m}$} & \multirow{2}{*}{$\begin{array}{c}11.3 \\
\text { million } \mathrm{m}^{3}\end{array}$} & $\mathrm{~m}^{3} /$ day \\
\hline & & & & 0.10 \\
\hline \multirow{2}{*}{$\begin{array}{c}\text { Jul. 4, } 2014 \\
\text { (by UAV) }\end{array}$} & \multirow{2}{*}{$1.08 \mathrm{~km}^{2}$} & \multirow{2}{*}{$74 \mathrm{~m}$} & \multirow{2}{*}{$\begin{array}{c}22.2 \\
\text { million } \mathrm{m}^{3}\end{array}$} & $\mathrm{~m}^{3} /$ day \\
\hline & & & & \\
\hline
\end{tabular}

\section{APPLICATION OF ANALYSIS DATA}

\subsection{Aerial photo interpretation map}

Aerial -photo interpretation map of Nishinoshima Volcano was created using the ortho-mosaic photo (Geospatial Information Authority of Japan, 2014a, b). The aerial photo interpretation map on March 22 is shown in Figure 7. The outline of result of interpretation is as follows.

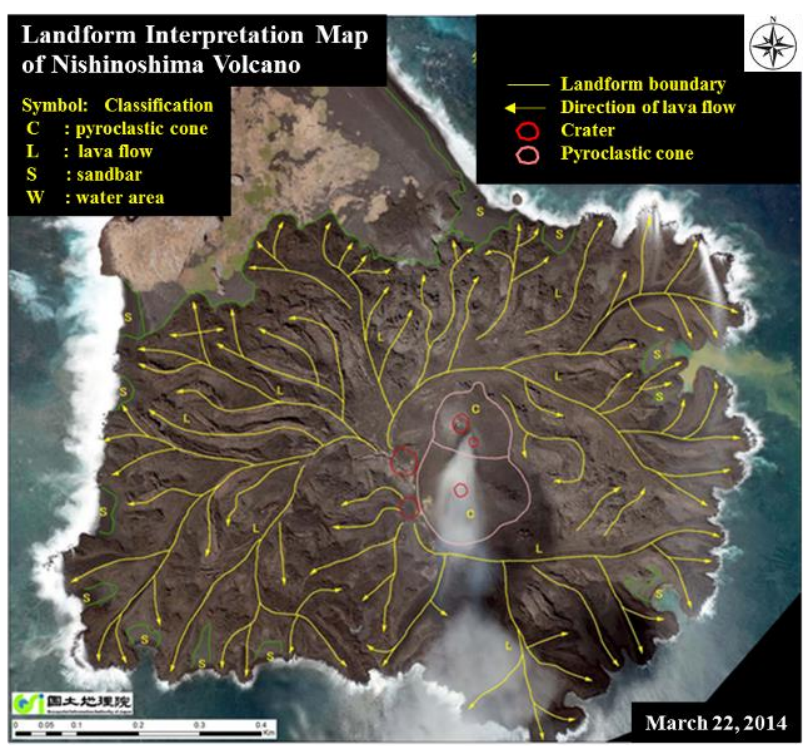

1) There are two pyroclastic cones. These are active with eruption of pyroclastic materials and smoke.

2) There are two craters. The lava flow down in all direction from these craters, and new land is expanding.

\subsection{3-D map}

3-D map created from ortho-mosaic photo and DEM data (Figure 8) was released on web site (Geospatial Information Authority of Japan, 2014c). This 3-D map can be operated such as rotation and zooming by a mouse.

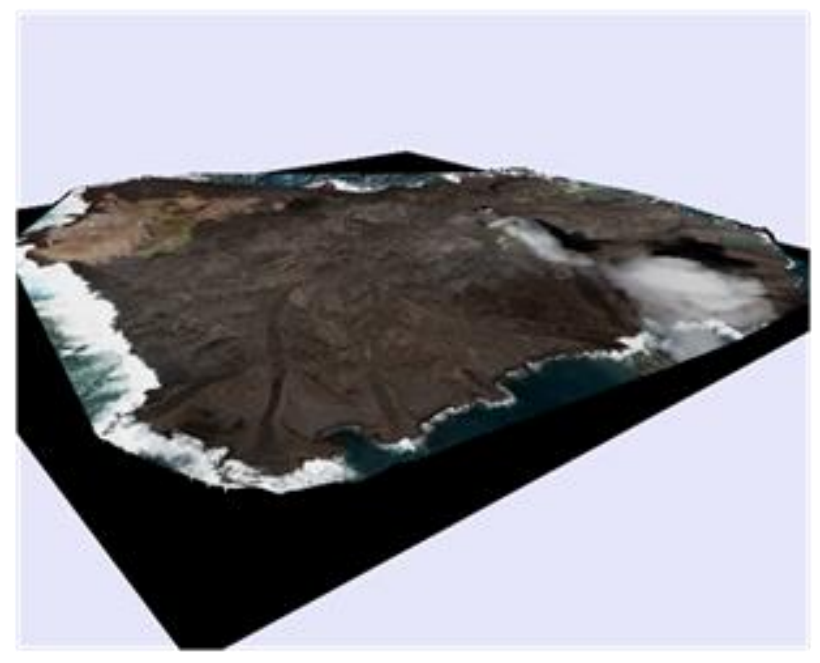

Figure 8 3-D map of Nishinoshima Volcano

\section{TECHNICAL EXPERIENCES AND ISSUES}

\subsection{Automated aerial photographing using a UAV}

1) It was verified that a UAV enables automated aerial photographing based on installed courses and altitudes for 130 km away point.

2) Gas engine type UAV can operate in the strong wind, but it is necessary to be careful for change of the photographing center-point position interval and increase of flight time compared with a manned airplane.

3) In the case of rising volcanic smoke, photographing from many directions and on many times are desirable.

4) In the case of high accuracy measurement using nonphotogrammetric camera, it is necessary to calibrate the camera. It is able to calibrate normally even if photographing through acrylic plate with $2 \mathrm{~mm}$ thickness.

5) Fixed iris of camera lens and automated shutter speed is better in the view of the camera calibration, but it is necessary to set the iris of camera lens properly against blurring and darkening of the image. Also, the problem didn't occur in the case of fixed shutter speed and automated iris of camera lens.

6) We acquired a high accuracy position data of a fixed UAV landing point by GNSS static observation in order to assure the accuracy of UAV position in the survey on July 4, 2014. The UAV position was calculated with high accuracy though accuracy of UAV position is low singly.

Figure 7 Aerial photo interpretation map of Nishinoshima Volcano (on March 22, 2014) 


\subsection{Analysis by "Pix4Dmapper" software}

1) "Pix4Dmapper" software is useful for automated generation tool of DEM and ortho-mosaic photo. However, on the analysis by this software, a rotation unstable of a whole block occurred even if we used aerial photos taken by photogrammetric airplane and camera (formal devices). In the overall aerial triangulation, when adjustments of aerial triangulation are implemented only the information of camera position without GCPs, the aerial triangulation on single photographing course become unstable according to undefined of rotation of a whole block. Therefore, GNSS data of camera position and photographing along plural parallel (or orthogonal) courses are required when there are no GCPs.

2) In the aerial photographing on the isolated island, GCPs are not often provided. When a high accuracy result is required, observation by photogrammetric airplane and camera is important because GNSS positioning accuracy of UAV is low.

\section{CONCLUSIONS}

In the Nishinoshima volcano, we performed automated aerial photographing using UAV and created ortho-mosaic photo and DEM data by SfM-MVS technique. Also, the area, volume, highest elevation and size transition could be estimated by analysis based on two measurement data. These result were utilized in the evaluation of volcanic activity, landform interpretation and creation of 3-D map, and then it indicates that UAV system and SfM-MVS technique are useful for landform monitoring in active volcano. These operations revealed new knowledge and problems to be solved on the photography and analysis using UAV.

\section{ACKNOWLEDGEMENTS}

We would thank to Ogasawara Village office on selection and secure space for UAV operation. A lot of application result were produced by Geocartographic Department and Geospatial information Department on Geospatial Information Authority of Japan.

\section{REFERENCES}

Agarwal, S., Snavely, N., Simon, I., Seitz, S.M. and Szeliski, R., 2009. Building Rome in a day. Computer Vision, 2009 IEEE 12th International Conference on, pp. 72-79.

Bendea, H., Boccardo, P., Dequal, S., Giulio Tonolo, F., Marenchino, D., and Piras, M., 2008. Low cost UAV for postdisaster assessment. In Proceedings of The XXI Congress of the International Society for Photogrammetry and Remote Sensing, Beijing, China, Vol. XXXVII. Part B8, pp. 1373-1380.

Gerke, M. and Kerle, N., 2011. Automatic structural seismic damage assessment with airborne oblique pictometry imagery. Photogrammetric Engineering \& Remote Sensing, 77(9), pp. 885-898.

Inoue, H., Uchiyama, S. and Suzuki, H., 2014. Multicopter Aerial Photography for Natural Disaster Research. Report of the National Research Institure for Earth Science and Disaster Prevention, 81, pp. 61-98. (in Japanese with English abstract)
Geospatial Information Authority of Japan, 2014a. http://www.gsi.go.jp/kenkyukanri/kenkyukanri60006.html (accessed 1 Sep. 2014).

Geospatial Information Authority of Japan, 2014b. http://www.gsi.go.jp/gyoumu/gyoumu41000.html (accessed 1 Sep. 2014).

Geospatial Information Authority of Japan, 2014c. http://saigai.gsi.go.jp/2/20131120nishinoshima/nishinoshima_3 d/20140322nishinoshima_all.html (accessed 1 Sep. 2014).

Maza, I., Caballero, F., Capitán, J., Martínez-de-Dios, J. R., and Ollero, A., 2011. Experimental results in multi-UAV coordination for disaster management and civil security applications. Journal of intelligent \& robotic systems, 61(1-4), pp. 563-585.

Lowe, D., 2004. Distinctive image features from scale-invariant keypoints. International journal of computer vision, 60 (2), pp. 91-110.

Rinaudo, F., Chiabrando, F., Lingua, A. M., and Spanò, A. T., 2012. Archaeological site monitoring: UAV photogrammetry can be an answer. The International archives of the photogrammetry, Remote sensing and spatial information sciences, 39(B5), pp. 583-588.

Snavely, N., Seitz, S. and Szeliski, R., 2006. Photo tourism: exploring photo collections in 3D. Proceedings of $A C M$ SIGGRAPH 2006, pp. 835-846.

Uchiyama, S., Inoue, H. and Suzuki, H., 2014. Approaches for Reconstructing a Three-dimensional Model by SfM to Utilize and Apply this Model for Research on Natural Disasters. Report of the National Research Institure for Earth Science and Disaster Prevention, 81, pp. 37-60. (in Japanese with English abstract)

Vallet, J., Panissod, F., Strecha, C. and Tracol, M., 2011. International Archives of the Photogrammetry, Remote Sensing and Spatial Information Sciences, ISPRS ICWG I/V UAVgconference, Zurich, Switzerland.

Watabe, Y. and Sassa, S., 2009. An Effective Investigation of Tidal Flat Sedimentation by Means of UAV and MASW. Journal of Japan Society of Civil Engineers, Ser. B2 (Coastal Engineering), 65(1), pp. 1441-1445. (in Japanese with English abstract)

Yan, J., Minai, A.A. and Polycarpou, M.M., 2003. Cooperative real-time search and task allocation in UAV teams. Decision and Control, Proceedings of 42nd IEEE Conference on (Volume: 1 ), DOI:10.1109/CDC.2003.1272527

Revised April 2014 